\title{
Artigos
}

\author{
Bárbara Nascimento Flores \\ Universidade Estadual de Santa Cruz/ UESC \\ Salvador Dal Pozzo Trevizan \\ Universidade Estadual de Santa Cruz/ UESC
}

\section{Ecofeminismo e comunidade sustentável}

\begin{abstract}
Resumo: O movimento de ecovilas representa uma alternativa de organização social de baixo impacto sobre os componentes naturais e de novos valores condizentes com o bem-estar de vida social. O movimento ecofeminista, por sua vez, sustenta que a defesa do meio ambiente constitui parte essencial do movimento feminista. Esta pesquisa investiga se, na organização e dinâmica da ecovila, os princípios do ecofeminismo estão presentes e se contribuem para a sustentabilidade ambiental da comunidade nas dimensões social, econômica e dos componentes naturais. Para efetuar esta avaliação, tomou-se como base empírica a Ecovila de Piracanga, localizada no município de Maraú, litoral sul da Bahia, Brasil. Os resultados sustentam o pressuposto de que o ecofeminismo tem estreita relação com a sustentabilidade do meio ambiente, em nível local, e apontam para a possibilidade de soluções inovadoras no relacionamento entre sociedade e natureza.
\end{abstract}

Palavras-chave: ecofeminismo; ecovilas; comunidades sustentáveis; desenvolvimento local.

Copyright (c) 2015 by Revista Estudos Feministas.

1 Muhammad YUNUS et al., 2010.

\section{Introdução}

O discurso da sustentabilidade do meio ambiente tem se tornado hegemônico, permeando desde mentes altruístas em defesa da conservação da natureza e da melhoria das condições de vida humana até aquelas que se utilizam desse mesmo discurso para se mostrarem simpáticas à opinião pública e, dessa forma, tirar proveitos próprios. O certo é que organismos internacionais constatam que é grande e crescente o número de pessoas, movimentos, empresas e governos que buscam alternativas de atuação em conformidade com a sustentabilidade em suas diversas dimensões, resultantes dos movimentos de reformas sociais e políticas que, nas décadas de 1960 e 1970, questionaram as bases que sustentam a sociedade atual. ${ }^{1}$ São movimentos que estão fazendo 
2 Fritjof CAPRA, 2000; Monique HÉBRARD, 1994.

${ }^{3}$ ROSS JACKSON, 2004; Marco Aurélio P. JORGE, 2008.

${ }^{4}$ Karen SVENSSON and Hildur JACKSON, 2002.

\footnotetext{
${ }^{5}$ BIANCHI, 2012.

6 WARREN E CHENEY, 1991; WARREN, 1994 e 2005.
}

7 Sherry ORTNER, 1974.

${ }^{8}$ D'EAUBONNE, 1974; MURARO 2002

\footnotetext{
${ }^{9}$ Françoise D'EAUBONNE, 1974.

${ }^{10}$ Rosemary RUETHER, 1995.
}

nascer um novo paradigma de organização social frente aos problemas ambientais. Argumenta- $\mathrm{se}^{2}$ que tais mudanças seriam o prenúncio de uma ética de abandono da perspectiva antropocêntrica, em favor de uma perspectiva global e sistêmica, na busca de valores mais integrativos, como cuidado, cooperação e conservação, os quais, no paradigma dominante, foram negligenciados e associados às mulheres. É nesse contexto que surgem movimentos com novas propostas de vida e de organização social, como o ecovila e ecofeminismo.

As primeiras ecovilas surgiram na década de $1970^{3}$ como alternativas de comunidades nas quais as pessoas se esforçam por levar uma vida em harmonia consigo mesmas, com os outros seres animados e inanimados e com a Terra. ${ }^{4}$

No mesmo período, surgiram também as primeiras manifestações do movimento feminista em defesa do meio ambiente. O termo ecofeminismo teria sido utilizado pela primeira vez em 1974, por Françoise d'Eaubonne, que, em 1978, fundou, na França, o movimento Ecologia e Feminismo. A relação entre ciência, mulher e natureza estaria entre as primeiras preocupações do movimento ecofeminista. ${ }^{5}$ Destaca-se no movimento ${ }^{6}$ que ecologia é um assunto feminista, mas que as semelhanças entre feminismo e ecologia têm sido esquecidas pela ciência ecológica, e essa vertente do movimento feminista, unindo o movimento das mulheres com o movimento ecológico, traz uma nova visão de mundo, desvinculada da concepção socioeconômica e de dominação.

Sherry Ortner ${ }^{7}$ chama à atenção ao fato de que, em todas as culturas, as mulheres têm sido alvo da subordinação, e propõe uma investigação profunda da origem da violência nas diferenças dos corpos entre homem e mulher. Argumenta ainda que a falta de uma função criativa no homem o levou a produzir uma função destrutiva de forma artificial, pela técnica.

Nessa abordagem, o ecofeminismo identifica no sistema patriarcal a origem da catástrofe ecológica atual, tendo sido a natureza e as mulheres, ambas associadas à reprodução da vida, o alvo das agressões desse sistema. ${ }^{8}$ Nessa perspectiva, o patriarcado se exprime com a mesma lógica do poder machista, opressor e totalitário da agroindústria, atacando os fundamentos da vida, na sua expressão simbólica mais profunda: a fecundidade do ser vivo. Daí a luta de feministas pela libertação da mulher oprimida, na relação de gênero, estar associada ao movimento ecofeminista de libertação da mulher e da natureza, ambas exploradas. De acordo com Françoise D'Eaubonne ${ }^{9} \mathrm{e}$ Rosemary Ruether, ${ }^{10}$ no passado, a agricultura teria sido uma tarefa feminina, mas, com a invenção do arado e da irrigação, os homens se apropriaram de dois recursos que pertenciam à 
1 WARREN, 2005

${ }^{12}$ Riane EISLER, 2007

${ }^{13}$ Susan GRIFFIN, 1978.

14 RUETHER, 1975.

${ }^{15}$ Mary MELLOR, 1997.

16 Yayo HERRERO, 2007.

${ }^{17}$ Rosângela ANGELIN, 2006. mulher: a agricultura e a fecundidade. Estudos apontam ${ }^{11}$ que o sistema patriarcal tem suas origens na filosofia da Grécia antiga e na tradição racionalista. Antes de invasões nômades vindas da Eurásia, o que havia na sociedade indo-europeia era um sistema familial, caracterizado como matrifocal ou matrilinear, numa era agrária de paz. Riane Eisler ${ }^{12}$ destaca como a parceria entre sexos, o cuidado com a beleza, a estética, a arte e a criatividade dominavam naqueles tempos reafirmando uma ética feminina.

Haveria, pois, necessidade urgente de vincular a luta pelos direitos das mulheres à luta em defesa da natureza. Pressupõe-se, segundo Susan Griffin, ${ }^{13}$ que a lógica da ciência seja contra a vida e contra a mulher, e que a superação de tal cenário de opressão seja feita de forma positiva e libertadora. Com o conhecimento de nossas origens, do nosso presente e dos nossos desejos, propõe a autora, pode-se conhecer as conexões entre a vida de cada planta, animal e ser humano, formando um só corpo com o planeta.

Ruether ${ }^{14}$ adverte que as mulheres precisam ver que não haverá libertação para elas nem solução para a crise ecológica, numa sociedade com relações de dominação, sendo necessário unir o movimento feminista com o movimento ecológico para vislumbrar mudança radical nas relações socioeconômicas e nos valores da moderna sociedade industrial. Mary Mellor ${ }^{15}$ acrescenta que as mulheres sofrem desproporcionadamente as consequências dos impactos ambientais no seu corpo (resíduos de dioxina na amamentação e distúrbios na gravidez) e no seu trabalho, como alimentadoras e cuidadoras.

Yayo Herrero ${ }^{16}$ sintetiza as propostas ecofeministas para um ambiente sustentável, da seguinte forma: oposição a um desenvolvimento de maximização de benefícios monetários, em detrimento da saúde das comunidades humanas e dos ecossistemas; incorporação e valorização dos saberes e trabalhos das mulheres envolvidas em atividades de subsistência; concentração na organização econômica e política da vida e do trabalho das mulheres que apresente alternativas à crise ecológica e melhoria das condições de vida das muIheres e dos pobres; busca da autossuficiência, da descentralização e da auto-organização, mediante a busca dos equilíbrios. Esse rol de propostas ecofeministas em defesa do meio ambiente, sintetizadas por Herrero, são contempladas por duas tendências ecofeministas: a espiritualista e a construtivista. De acordo com Rosângela Angelin, ${ }^{17}$ existem três tendências ecofeministas: a clássica, a espiritualista e a construtivista. A clássica vê no homem uma predisposição natural para a competição e a destruição, e sua obsessão pelo poder o leva a guerras suicidas, ao envenenamento e à destruição do planeta, enquanto a ética feminina de proteção dos seres 
vivos se opõe a essa agressão, buscando a igualdade, o pacifismo e a conservação da natureza. A espiritualista, fundamentada nos princípios religiosos de Ghandi e da Teologia da Libertação, argumenta que o desenvolvimento tem gerado um processo de violência contra a mulher e o meio ambiente, e luta contra a dominação, o sexismo, o racismo, o elitismo e o antropocentrismo, atribuindo à mulher uma tendência protetora da natureza. A construtivista, embora não se identifique com as duas primeiras, compartilha com elas ideias antirracistas, antiantropocêntricas e anti-imperialistas, negando, porém, a relação da mulher com a natureza como uma característica intrínseca do sexo feminino, mas sim da responsabilidade de gênero resultante da divisão social do trabalho, da distribuição do poder e da propriedade.

Embora partam de pressupostos conflitantes, particularmente a abordagem clássica e a construtivista, presumese, nas três tendências, uma forte relação entre mulher/feminilidade-natureza, mais intensa do que a relação homem/ masculinidade-natureza, fazendo da mulher mais cuidadosa com a natureza. O que difere nas três abordagens é a origem dessa relação: enquanto na tendência clássica a explicação das diferenças está na própria natureza do homem/masculino ser agressivo e destrutivo, na tendência espiritualista, a explicação das diferenças encontra-se no processo do desenvolvimento "selvagem", que teria descuidado da finitude e capacidade de resiliência da natureza, e, na tendência construtivista, a explicação é cultural, produto da divisão social do trabalho e de uma estrutura social marcada pela desigualdade. Embora as tendências espiritualista e construtivista neguem a relação de gênero com o meio ambiente como um fenômeno natural, como ocorre na abordagem clássica, nas três tendências, independentemente de mitos ou da realidade que envolve o discurso de cada abordagem, todas admitem haver uma forte relação do ecofeminismo com a proteção do meio ambiente.

18 Bruna BIANCHI, 2012.

Para Bruna Bianchi, ${ }^{18}$ o ecofeminismo, especialmente nas abordagens culturalista (ou construtivista) e espiritualista, tornou-se objeto de estudo acadêmico, de cursos universitários e de conferências, nas décadas de 70 e 80 do século $X X$, reunindo representantes de movimentos ambientalistas de todo o mundo. Nos protestos contra lixo tóxico e pesticidas, descreve Bianchi, as mulheres têm desempenhado um papel de vanguarda. Segundo ela, os movimentos espontâneos de mulheres em todo o mundo revelaram a ligação entre saúde e vida das mulheres com a destruição da natureza. $A$ possível destruição do planeta pelo uso da tecnologia tem estado entre as principais preocupações nas manifestações dos movimentos ecofeministas, tanto nos Estados Unidos quanto na Inglaterra, nos anos 80 . No Brasil, referindo-se à

14 Estudos Feministas, Florianópolis, 23(1): 11-34, janeiro-abril/2015 
${ }^{19}$ CARNEIRO, 2012, p. 1.

20 Ynestra KING, 1997.

${ }^{21}$ GARCIA, 1992, p. 164

${ }^{22}$ Catriona SANDILANDS, 1999.

${ }^{23}$ Emma SILIPRANDI, 2009.

${ }^{24}$ DI CIOMMO, 2003; PLANT, 1990

${ }^{25}$ SVENSSON E JACKSON, 2002 SANTOS JR., 2006.

${ }^{26}$ PLANT, 1990.
Rio-92, Beatriz Carneiro destaca que, "antes desse evento, as mulheres já estavam presentes e atuantes na mobilização pela proteção ambiental, na construção das políticas ambientais." 19 Ynestra King ${ }^{20}$ enfatiza que para a maior parte das mulheres do mundo o interesse na preservação da terra, água, ar e energia não é uma abstração, e sim uma clara parte do esforço para simplesmente sobreviver.

Essa relação de vínculo entre mulher e natureza não é algo pacífico no movimento feminista, nem no movimento ecofeminista. Segundo Sandra Garcia, "a dicotomia cultura/ natureza não é universal, e nem há uma uniformidade de significados atribuídos à natureza, à cultura, ao masculino e ao feminino." 21 Catriona Sandilands ${ }^{22}$ argumenta que o foco do ecofeminismo não está na identidade mulher-natureza, mas na relação democrática entre gênero e natureza. Por outro lado, Emma Siliprandi, ${ }^{23}$ entre outras, sustenta que é inegável a associação entre mulher e ecologia, pois existe uma convergência entre a forma como o pensamento ocidental hegemônico vê as mulheres e a natureza, ou seja, a dominação das mulheres e a exploração da natureza como dois lados da mesma moeda. Nessa mesma linha de pensamento, argumenta-se ainda ${ }^{24}$ que mulheres e natureza têm tido uma longa associação através da história, mas somente agora essa profunda associação vem sendo compreendida.

No contexto da sociedade técnico-científica-informacional da década de 90 do século $\mathrm{XX}$, as comunidades conhecidas como ecovilas tornam-se experiências institucionalizadas, tendo como parâmetro a sustentabilidade. ${ }^{25} \mathrm{Se}$ a construção de novas relações de gênero e de novas relações humanas com a natureza é condição sine qua non para a construção de comunidades sustentáveis, ${ }^{26}$ é de se esperar que as ecovilas sejam contextos sociais favoráveis para a prática dos princípios ecológicos do movimento ecofeminista, no qual se inserem relações de igualdade respeitando as diferenças, contrárias à dominação de gênero, assim como dos princípios de sustentabilidade ambiental, defendidos pelo movimento das ecovilas.

Para esta pesquisa, o foco da atenção está em identificar na comunidade em que medida estão presentes o discurso e as práticas ecofeministas, quaisquer que sejam as tendências, e poder associar a elas práticas em defesa do meio ambiente.

O pressuposto ecofeminista de que haja uma intrínseca conexão desse movimento com a conservação do meio ambiente permite supor que, uma vez caracterizada a presença do ecofeminismo na ecovila, desenvolvam-se ali práticas ambientalmente sustentáveis. Essa relação entre os dois movimentos constitui o referencial para avaliar em que medida as propostas para a construção de uma sociedade mais 
27 BRUNDTLAND, 1991.

${ }^{28}$ Oluf LANGHELLE, 2000.

${ }^{29}$ ALIIERI and NICHOLLS, 2005; and ZAMBERLAN and FRONCHETI, 2001.

${ }^{30}$ Ignacy Sachs, 1993. condizente com o respeito à natureza e às relações humanas se aproximam do real concreto, e não apenas do real pensado idealmente. Mais especificamente, busca-se avaliar em que medida os princípios do ecofeminismo estão presentes na dinâmica da ecovila e em que medida tais princípios estão relacionados com práticas de sustentabilidade ambiental desse tipo de comunidade. Tal avaliação pode ser implementada mediante a identificação de indicadores que representem valores defendidos pelo ecofeminismo, associados com indicadores que representem a sustentabilidade ambiental da comunidade.

\section{Fundamentação Teórica}

O ponto de partida para analisar a relação entre ecofeminismo e a sustentabilidade ambiental de comunidades nasce do pressuposto de que a existência de práticas sustentáveis está na base da organização e da dinâmica da ecovila, e do pressuposto de que os princípios que norteiam as ações do movimento ecofeminista estão em estreita sintonia com a sustentabilidade do meio ambiente. A ideia de sustentabilidade, por sua vez, traz consigo a noção de duração no tempo: o desenvolvimento que não esgota os recursos para o futuro. ${ }^{27}$ Assim, o conceito de sustentabilidade limita-se à conservação dos recursos no correr do tempo, isto é, uma reprodução vegetativa. Tal concepção é satisfatória quando nos referimos ao uso dos recursos naturais, mas, com a presença humana, a sustentabilidade ambiental não se realiza com a reprodução vegetativa: depende também de melhoria nas condições de vida, em função das expectativas que forem sendo geradas. De acordo com Oluf Langhelle, ${ }^{28} \mathrm{O}$ primeiro objetivo do desenvolvimento sustentável é o atendimento das necessidades humanas. A sustentabilidade ambiental está associada às condições de vida dos indivíduos ou das comunidades. ${ }^{29}$ Referindo-se aos princípios do ecodesenvolvimento, Ignacy Sachs ${ }^{30}$ relaciona: satisfação das necessidades básicas, solidariedade com as gerações futuras, participação da população envolvida, preservação dos recursos naturais, elaboração de um sistema social que garanta emprego, segurança social e respeito a outras culturas. Portanto, além da durabilidade dos componentes naturais, a sustentabilidade ambiental de uma comunidade envolve a sensação de bem-estar e de felicidade individual e coletiva. Tal sensação, entretanto, não se dá no abstrato, mas nas possibilidades reais de atendimento às necessidades, materiais e não materiais, sentidas pelos membros da coletividade, como habitação, alimentação, saúde, educação, segurança, informação, entre outras. Assim, o capital social da comunidade - entendido como o conjunto das

16 Estudos Feministas, Florianópolis, 23(1): 11-34, janeiro-abril/2015 
${ }^{31}$ NORTH, 1990; PUTNAM, 1993.

32 James S. COLEMAN, 1988.

${ }^{33}$ Robert PUTNAM, 1993.
${ }^{34}$ CUNHA, 2010; EAST, 2005; SVENSSON and JACKSON, 2002; OLIVEIRA, 2003; e SILIPRANDI, 2000 .

${ }^{35}$ HERRERO, 2007

${ }^{36}$ ANGELIN, 2006. instituições que oferecem esses serviços e o acesso que os membros da comunidade têm aos serviços, tornando-lhes possíveis as condições de bem-estar e de felicidade - define o nível de sustentabilidade ambiental da comunidade. As instituições sociais têm sido vistas como um tipo de capital social fundamental para o desenvolvimento das condições de vida individual ou em comunidade. ${ }^{31}$ Instituições fisicamente estabelecidas são as que tornam concretamente viável o acesso aos bens e senviços. Como exemplo, JamesS. Coleman ${ }^{32}$ destaca o papel das normas eficazes como forças poderosas para evitar o interesse próprio e levar a agir pelo interesse coletivo. Robert Putnam ${ }^{33}$ identificou, na densidade de associações e na existência de relações sociais de reciprocidade, as principais premissas para prosperidade.

Em síntese, no que se refere à dimensão dos componentes naturais da comunidade, a sustentabilidade ambiental diz respeito à duração deles; no que diz respeito à dimensão econômica, a sustentabilidade refere-se à capacidade de reprodução da vida e satisfação das necessidades ao longo do tempo; e, no que se refere à dimensão social, a sustentabilidade diz respeito às possibilidades de vida social e de bem-estar na comunidade, ao longo do tempo. Tanto o ecofeminismo quanto as ecovilas propõem: (a) descentralização do poder, não hierarquização e democracia direta; (b) apoio ao comércio justo e a uma economia ecológica e solidária como modelo de desenvolvimento; (c) insistência em tecnologia de baixo impacto e não agressiva ao meio ambiente; (d) ênfase no caráter local das ações para garantir a segurança alimentar e a moradia; (e) relações equilibradas entre sexos, classes e raças, e com o meio ambiente. ${ }^{34}$

\section{Procedimentos metodológicos}

Delineou-se uma metodologia para avaliar a interação entre indicadores de sustentabilidade ambiental, nas dimensões social, econômica e dos componentes naturais envolvidos nas atividades produtivas e de consumo da comunidade, com indicadores que representam os princípios (valores) defendidos pelo ecofeminismo. A partir da literatura sobre ecofeminismo considerada neste trabalho, particularmente da síntese de propostas ecofeministas apresentadas por Herrero ${ }^{35}$ e das tendências ecofeministas de Angelin, ${ }^{36}$ foram selecionados valores ecofeministas, independentemente de suas tendências passíveis de observação empírica, tais como: inclusão social, organização não hierarquizada, ausência de práticas discriminatórias quanto à raça, classe social, religião e ao gênero nas famílias e na comunidade, processos de tomada de decisão e exercício do poder; capacidade de desenvolvimento de uma economia em nível 
${ }^{37}$ SACHS, 1993.

${ }^{38}$ Amartya SEM, 2000. local, igualdade de oportunidades de acesso aos bens e serviços, igualdade de gênero na divisão do trabalho; e a presença ou não de práticas e/ou atitudes conservacionistas, especialmente em termos de investimento em tecnologias de baixo impacto e de relações de interdependência com a natureza, de forma a respeitar a capacidade de regeneração dos componentes naturais dentro do ecossistema. A partir desses valores, elaborou-se uma matriz de indicadores ecofeministas, constantes da Tabela 1.

Paralelamente, foram definidos indicadores de sustentabilidade ambiental da comunidade, nas três dimensões indicadas, para serem correlacionados com os indicadores de ecofeminismo. Para a sustentabilidade ambiental, na dimensão social, foram definidos indicadores relacionados à melhoria das condições de vida, participação no plano político, cooperação e identidade local. Na dimensão econômica, considerou-se a capacidade da comunidade na geração de renda e emprego. Na dimensão dos componentes naturais, considerou-se o uso/gestão de recursos envolvidos nas atividades de produção e consumo da comunidade, como uso da água, gestão de efluentes líquidos e de resíduos sólidos.

Como mecanismo de validade interna das matrizes de indicadores de sustentabilidade ambiental da comunidade, utilizou-se a correlação de Spearman para eliminar indicadores que não apresentassem correlação significante com, pelo menos, um indicador, dentro da mesma dimensão (os indicadores constantes das Tabelas de 2 a 4, apresentados no item 4. Resultados e Discussão, são os que apresentaram correlação significante com, pelo menos, um indicador dentro da respectiva matriz). A métrica de cada indicador foi estruturada numa escala de cinco categorias de respostas, com pontuação variando de 0 a 4.

Optou-se por tomar como base empírica de análise uma ecovila já consolidada, localizada na região de influência da Universidade Estadual de Santa Cruz (UESC), no litoral Sul da Bahia, a Ecovila de Piracanga, no município de Maraú, nas coordenadas 1412‘52.09" S e 3859'31.74" W. A importância do local como escala de análise e de intervenção tem sido destacada por autores como Sachs ${ }^{37}$ e Amartya Sen. ${ }^{38}$

O nível de sustentabilidade ambiental, nas três dimensões, pode ser formalmente representado na seguinte equação:

Nível de sustentabilidade ambiental da comunidade,

$$
\text { na dimensão } y=\text { "(XPij/M)/n (1) }
$$

sendo Xi o entrevistado, j o indicador de sustentabilidade, $\mathrm{P}$ a pontuação obtida pelo entrevistado i, referente ao indicador j, que varia de 0 a 4, $N$ o número de entrevistados que 
responderam ao indicador j, e $n$ o número de indicadores da respectiva dimensão.

Em síntese, o nível de sustentabilidade ambiental em cada dimensão é dado pela média aritmética de pontos obtidos, considerando as respostas dos entrevistados, na respectiva dimensão. Sendo 4 o escore médio máximo possível, em cada dimensão, para fins comparativos, considera-se útil dividir o escore obtido pelo escore máximo possível. Neste caso, o índice de sustentabilidade varia de 0 a 1.

A tomada de dados foi realizada em um período de vivência contínua de 4 meses na comunidade, no ano de 2012, efetuando observação direta com registros diários, registros fotográficos, entrevistas semiestruturadas e aplicação de questionários estruturados, tudo com a anuência prévia da liderança da comunidade e consentimento prévio, livre e esclarecido de cada entrevistado, assim como a aprovação do comitê de ética em pesquisa da Universidade Estadual de Santa Cruz (UESC), BA.

\section{Resultados e discussão}

\subsection{Caracterização das atividades na comunidade}

As pessoas envolvidas diretamente com o sistema econômico interno prestavam serviços comunitários relativos à produção ou à saúde, à educação e à área administrativa ( $46 \%$ ); $27 \%$ eram crianças e adolescentes, e outros $27 \%$ tinham rendimentos independentes do sistema econômico interno. Como se trata de uma comunidade envolvida em serviços turísticos, sua infraestrutura é capaz de oferecer lazer, dar atendimento à saúde e à espiritualidade, com hospedagem, transporte, alimentação, cursos e terapias, num centro holístico, dando assistência para os membros da comunidade e pessoas externas que o procuram. Os serviços oferecidos são pagos, o que movimenta a economia interna do Centro.

O setor administrativo concentra o maior número de pessoas da comunidade, predominando as do sexo feminino, com funções de coordenação, gerência, recepção e administração financeira. Os setores divididos mais equilibradamente entre homens e mulheres eram os relacionados à cozinha, carpintaria, marcenaria, motorista, babysiter, jardinagem, e serviços relacionados à saúde e à educação. O único setor com maior número de pessoas do sexo masculino era o relacionado à produção (construtores, permacultores e agricultores). No setor das artes, somente pessoas do sexo feminino estavam envolvidas, exercendo atividades de dança, pintura, teatro, artesanato, entre outras.

No período da pesquisa, a comunidade era constituída de 92 pessoas (adultos e crianças), habitando 42 unida- 
des residenciais, numa área de 100 ha. Dentre estas unidades, 32 adultos, participaram espontaneamente das entrevistas. Nas unidades residenciais pesquisadas, foram identificadas 67 pessoas de diferentes nacionalidades, das quais $69 \%$ estavam na faixa etária entre 19 e 60 anos, e os demais eram bebês, crianças e adolescentes, entre 0 e 18 anos, com exceção de uma pessoa na categoria de idosa. O nível de escolaridade encontrado é relativamente elevado, se considerarmos que $67 \%$ concluíram o ensino médio para cima, e 33\% frequentavam o ensino fundamental, sendo crianças $27 \%$ das pessoas das residências pesquisadas, muitas das quais fora da idade escolar.

Em termos econômicos, a primeira vista, parece que se trata de uma população de baixa renda, já que em 50\% das unidades residenciais informou-se uma renda familiar per capita de um salário mínimo ou menos. Entretanto, considerando que $27 \%$ de residências pesquisadas tinham rendimentos outros, independentes da comunidade, esses quantitativos, em termos de salários mínimos, não dão um retrato da real situação econômica da comunidade.

Foram identificadas atividades tipicamente agrícolas, tais como o cultivo de hortaliças e o plantio agroflorestal, e atividades não agrícolas, como ecoturismo e turismo religioso, desenvolvidas na ecovila. No entanto, ainda não existia produção significativa, a ponto de abastecer as necessidades internas. Isto se explica pela recente implantação de atividades que requerem preparo do solo, que é arenoso, para o plantio mais intensivo no futuro. Sendo assim, grande parte dos alimentos consumidos na ecovila eram adquiridos nos municípios vizinhos.

\subsection{A presença do ecofeminismo na organização social da comunidade}

Analisando-se indicadores consistentes com os valores defendidos pelo ecofeminismo (Tabela 1), foram destacados aspectos, como a divisão de tarefas em casa e na comunidade, e os valores associados a cada tarefa, indicando papéis sociais não rígidos; a igualdade na expansão dos direitos civis, ou seja, autonomia quanto à participação no mundo político, econômico e social; a valorização da parceria, cooperação e instituições vinculadas entre si (família, governança, escola), em que predomina a governança circular; a diversidade e flexibilidade de decisão e ação; o agrupamento de unidades sociais menores (cooperativas, grupos de compartilhamento de conhecimentos, etc.); a valorização de serviços comunitários e voluntários (cuidado com crianças, escola, manutenção etc.); os adultos como responsáveis por todas as crianças (o mais precioso produto social); as políticas 
sociais para os mais necessitados; a valorização da beleza, da estética, da arte e da criatividade.

De acordo com relatos obtidos dos moradores, o ecofeminismo está relacionado à produção da vida, ao equilíbrio e respeito à natureza, assim como à valorização da mulher dentro de suas comunidades e à promoção dos direitos humanos. Para outros, a presença de ecofeminismo na comunidade está relacionada ao cuidado, à sensibilidade e à cooperação. Uma moradora assim se manifesta:

O ecofeminismo está relacionado com o novo modelo civilizatório que se busca; precisamos reaprender o que é gerar a vida e cuidar da vida. O grande valor de nossa época é o cuidado e quando homens e mulheres entram em contato com este valor, o vínculo entre todas as relações é restabelecido.

Tabela 1 - Nível de concordância dos entrevistados quanto à presença de cada indicador de ecofeminismo na Ecovila de Piracanga.

\begin{tabular}{|c|c|c|c|c|c|c|c|}
\hline Indicadores do ecofeminismo & $\begin{array}{l}\text { A } \\
(0)\end{array}$ & $\begin{array}{c}\mathrm{B} \\
(1) \\
\end{array}$ & $\begin{array}{c}\mathrm{C} \\
(2) \\
\end{array}$ & $\begin{array}{c}\mathrm{D} \\
(3) \\
\end{array}$ & $\begin{array}{l}\text { E } \\
(4) \\
\end{array}$ & $\mathrm{F}$ & Total \\
\hline $\begin{array}{l}\text { 1. A comunidade valoriza atitudes e práticas de } \\
\text { cooperação de parcerias. }\end{array}$ & 1 & 4 & 7 & 19 & 1 & 0 & 32 \\
\hline $\begin{array}{l}\text { 2. Existe harmonia, cuidado e apoio entre as pessoas da } \\
\text { comunidade. }\end{array}$ & 0 & 1 & 5 & 8 & 17 & 1 & 32 \\
\hline $\begin{array}{l}\text { 3. Existem oportunidades iguais aos membros da } \\
\text { comunidade de desenvolverem seus talentos. }\end{array}$ & 1 & 4 & 2 & 8 & 16 & 1 & 32 \\
\hline $\begin{array}{l}\text { 4. Existem oportunidades iguais aos membros da } \\
\text { comunidade se expressarem politicamente. }\end{array}$ & 0 & 7 & 5 & 7 & 12 & 1 & 32 \\
\hline $\begin{array}{l}\text { 5. Qualidades estéticas como beleza, arte e harmonia são } \\
\text { valorizadas na comunidade. }\end{array}$ & 0 & 4 & 2 & 7 & 18 & 1 & 32 \\
\hline $\begin{array}{l}\text { 6. A diversidade é valorizada e incentivada para a saúde } \\
\text { global e êxito da comunidade; }\end{array}$ & 1 & 4 & 0 & 10 & 16 & 1 & 32 \\
\hline $\begin{array}{l}\text { 7. A organização da comunidade é constituída de forma } \\
\text { não hierarquizada. }\end{array}$ & 11 & 3 & 6 & 6 & 5 & 1 & 32 \\
\hline $\begin{array}{l}\text { 8. A comunidade está organizada para apoiar seus } \\
\text { moradores com necessidade especiais, como pobres, } \\
\text { enfermos, deficientes físicos e mentais. }\end{array}$ & 3 & 6 & 4 & 7 & 11 & 1 & 32 \\
\hline $\begin{array}{l}\text { 9. O manejo e a recuperação dos ecossistemas é uma } \\
\text { preocupação da comunidade. }\end{array}$ & 0 & 0 & 2 & 9 & 20 & 1 & 32 \\
\hline $\begin{array}{l}\text { 10.Os membros da comunidade se empenham para } \\
\text { estabelecer relações entre si e a natureza. }\end{array}$ & 0 & 1 & 4 & 9 & 17 & 1 & 32 \\
\hline $\begin{array}{l}\text { 11. Desenvolvem-se, na comunidade, atividades de } \\
\text { celebração da vida e do amor, abrindo as mentes e os } \\
\text { corações dos membros para um plano maior. }\end{array}$ & 1 & 0 & 6 & 3 & 21 & 1 & 32 \\
\hline $\begin{array}{l}\text { 12. Há uma distribuição justa do poder (quem toma } \\
\text { decisões) na comunidade. }\end{array}$ & 6 & 4 & 4 & 8 & 9 & 1 & 32 \\
\hline $\begin{array}{l}\text { 13. A comunidade considera que o planeta é um } \\
\text { organismo vivo. }\end{array}$ & 0 & 0 & 2 & 4 & 25 & 1 & 32 \\
\hline
\end{tabular}

Fonte: Elaboração dos autores

Legenda: A - Nunca; B - Raramente; C - Frequentemente; D - Geralmente; E - Sempre; F - Sem resposta. 
Em Piracanga, as mulheres podem ser vistas atuando em diferentes ambientes e funções; elas são bastante representativas e ativas dentro da comunidade; ocupam postos de liderança, inclusive, de liderança espiritual. O pressuposto de que a comunidade está organizada de forma não hierarquizada (indicador 7) é o único, entre os 13 indicadores, em que mais de $50 \%$ dos entrevistados discordam. Apenas 11 (35\%) dos que responderam à entrevista concordam geralmente ou completamente que tal característica se manifesta na comunidade. Quanto aos demais indicadores, a maioria concorda geralmente ou completamente, destacando-se a recuperação dos ecossistemas e a percepção do planeta Terra como um organismo vivo (indicadores 9 e 13), ambos com 29 (93\%) dos entrevistados. Além destes, ainda se destacam, na concordância dos moradores, os indicadores $6 \mathrm{e}$ 10 , com a valorização da diversidade e um empenho para estabelecer relações entre eles e a natureza, com $81 \%$ de aprovação.

Mesmo que haja uma intenção de governança circular, isto é, de alternância de pessoas exercendo funções de decisão, ainda prevalece na comunidade a concentração das decisões em alguns membros. Apenas 17 (55\%) concordam geralmente ou completamente que há na comunidade uma distribuição justa do poder (indicador 12). É visível, na ecovila, a prevalência de decisões autoritárias de um pequeno grupo, mais próximo aos fundadores. Outros se sentem excluídos deste processo de decisões por não pertencerem ao grupo dominante, identificado como Inkiri, ou por se sentirem constrangidos em expor suas opiniões.

Quanto às tarefas e funções dentro da comunidade, não é possível identificar com clareza alguma divisão de gênero. A predominância de mulheres na maior parte das tarefas e funções deve-se, principalmente, ao fato de que, nesta comunidade, elas representam o maior número dos moradores. O grande número de reuniões com a participação dos membros da comunidade sugere que ali vigora o respeito à diversidade e a flexibilidade de decisão e ação. Entretanto, nem todos podem participar onde prevalecem decisões unilaterais dos líderes, conforme observação direta feita em campo e relatos de alguns moradores que levantam a questão de uma inversão das formas de dominação. Sobre isso, um morador se manifesta nos seguintes termos:

Piracanga é uma comunidade que, até o momento, tem características dominantes de uma comunidade matriarcal. As mulheres dominam, detêm o poder de decisão e o poder espiritual, controlam as forças produtivas, assim como o destino das pessoas, enfatizam a hierarquia espiritual e social, e os homens trabalham para manter a estrutura. 
${ }^{39}$ Fritjof CAPRA, 2000.
As observações e depoimentos revelam que a liderança da comunidade é das mulheres. Além de ser numericamente expressivo, o quantitativo de mulheres atuantes utiliza práticas de dominação entre pessoas e controle do poder interno, traduzindo-se em segregação de grupos e, muitas vezes, em visão utilitarista da natureza, no mesmo estilo ao que, segundo Fritjof Capra, ${ }^{39}$ ocorre nas instituições da sociedade hegemônica, dominada pelos homens.

A divisão de tarefas dentro de casa, com relação aos entrevistados casados, é predominantemente compartilhada, nas principais atividades, como limpar a casa, lavar a louça, preparar a comida, cuidar das crianças e exercer trabalhos fora de casa. Nesse aspecto, os entrevistados concordam que não existe na comunidade tarefa específica de homem ou de mulher, como defendido pelo ecofeminismo. A imagem bastante comum de pais cuidando dos filhos e de mães exercendo tarefas exteriores ao ambiente doméstico pode ser identificada como um indicador de que os papéis sociais de homens e mulheres na Ecovila de Piracanga não são rígidos.

Existe cooperação e parceria entre as instituições (famílias, governança, escola) que buscam manter vínculos entre si para o desenvolvimento das atividades comunitárias, e ainda iniciativas dos moradores de se juntarem para compartilhar conhecimentos e práticas em agrupamentos de unidades sociais menores, como os grupos de mães e gestantes, de estudos e práticas permaculturais, de artes e danças circulares, de espiritualidade, de esporte e lazer, de educação, entre outros. As tarefas de cuidado com crianças dentro e fora do ambiente escolar, bem como a prestação de serviços comunitários, são práticas disseminadas na comunidade. Não se observaram práticas de exploração de mulheres, nem de utilização de componentes naturais sem custos, a serviço do acúmulo de capital, pois as mulheres possuem lugar de destaque nessa organização social e há incentivo ao desenvolvimento de tecnologia para a produção artesanal e iniciativas para contabilizar os custos ambientais de produtos. Além disso, os entrevistados descrevem o trabalho na comunidade como prazeroso, contribuindo para o bem coletivo. No entanto, não há uma proposta sistematizada de responsabilidade socioambiental e de economia solidária, com o intuito de fortalecer a economia e o desenvolvimento locais, o que representa um risco às oportunidades de geração de renda, à medida que a população da comunidade aumenta.

Apesar das iniciativas de equidade social, ainda prevalecem relações de trabalho em que o centro holístico, dominando os principais meios de produção, beneficia-se desproporcionadamente da oferta de serviços, como moradia e alimentação, do trabalho voluntário e da mão de obra barata local. Existem questionamentos quanto à prestação de contas 
e às restrições ao fomento de atividades internas para a geração de renda.

As pessoas do grupo Inkiri concordam que a comunidade está preparada para apoiar aqueles com necessidades especiais, em caso de pobreza e/ou deficiências, pois possuem apoios e financiamentos relacionados à moradia, alimentação e participação em projetos da comunidade e têm acesso a fundos comunitários ao contribuírem com serviços comunitários. Já os não Inkiris não concordam com esse indicador, pois não têm acesso a nenhum dos benefícios e, conforme relatos, já houve casos em que pessoas tiveram de se retirar da ecovila por não se enquadrarem ao perfil exigido.

Quanto à presença do ecofeminismo em ações que promovem a vida, levando em consideração o valor intrínseco da natureza, onde as pessoas enxergam o planeta como organismo vivo, destacam-se aquelas que priorizam tecnologias de baixo impacto nas construções, como técnicas de bioarquitetura; prevenção e uso da medicina natural (fitoterapia, massagens, terapias holísticas); investimentos em agrofloresta e permacultura, enfatizando o caráter local das ações, no plantio e colheita, considerando a diversidade, a complementariedade e os ciclos naturais (observando fases da lua e estações do ano); e a realização de experiências alternativas de recuperação ambiental e segurança alimentar. A integração e interdependência com a natureza pode ser percebida por meio do entrelace de antigos mitos com ideias modernas de interdependência entre tudo e todos, no qual expressões do planeta como a Mãe-Terra podem ser ouvidas frequentemente, principalmente nos momentos de espiritualidade, nos quais os moradores se juntam para celebrar a vida e o amor, por meio de rituais da lua cheia, círculos de mulheres da lua nova, retiros espirituais dos quatro elementos (fogo, terra, água e ar), batizados, nascimentos e casamentos.

Em síntese, o desequilíbrio na distribuição de poder entre homens e mulheres, e a estrutura hierarquizada da comunidade são os grandes desafios que ainda persistem, no sentido de contemplar os princípios e valores defendidos pelo movimento do ecofeminismo, na Ecovila de Piracanga.

\subsection{A sustentabilidade ambiental da comunidade}

O nível de sustentabilidade ambiental, na dimensão social, foi avaliado mediante indicadores que expressassem a percepção dos residentes quanto às possibilidades de vida social e de bem-estar na comunidade, com foco nas relações interpessoais e coletivas, na segurança, na discriminação social, no acesso a bens e serviços da comunidade, como saúde, educação, transportes, entre outros, conforme a

24 Estudos Feministas, Florianópolis, 23(1): 11-34, janeiro-abri/2015 
Tabela 2. Dentro de uma escala que varia de 0 a 4 , a comunidade atingiu média de 2,916 , com variação que vai de 2,156 , para o indicador 8 -O sistema de comunicação atende os interesses da comunidade-, a 3,750, para o indicador 3 As crianças podem brincar e passear livremente pelas ruas e praças da comunidade -, indicando que 29 (90\%) concordam que se trata de uma comunidade na qual reina a segurança e a tranquilidade nos espaços públicos. Numa variação de 0 a 1, o nível de sustentabilidade é de 0,729.

Os indicadores relacionados à sustentabilidade na dimensão econômica foram selecionados para dimensionar a capacidade de acesso aos bens e serviços e às atividades geradoras de renda dos membros da comunidade. Para tanto, considerou-se o nível de renda familiar per capita, a absorção de mão de obra local e a satisfação das necessidades básicas de moradia e alimentação, conforme a Tabela 3. Obtevese a média de 2,499 pontos, numa escala que varia de 0 a 4 , ou 0,6247 , numa escala de 0 a 1 . Merecem especial destaque os indicadores 1, 6 e 7, em razão da situação contrária que representam: no primeiro caso, 28 (87\%) dos entrevistados concordam que satisfazem suas necessidades de alimentação e de moradia na comunidade, enquanto, no segundo caso, 24 (75\%) discordam que os alimentos consumidos são produzidos na comunidade ou, no terceiro caso, 16 (50\%) discordam que o nível de renda familiar per capita na ecovila permite um padrão de vida digno. Essa controvérsia pode ser entendida quando $50 \%$ dos entrevistados informam um baixo nível salarial, enquanto $27 \%$ dos moradores têm rendimentos provindos de fora da comunidade.

Para dimensionar o nível de sustentabilidade na dimensão dos componentes naturais, foram selecionados indicadores envolvendo atividades relacionadas com água, solo, energia, gestão dos resíduos e dos efluentes, entre outros, conforme a Tabela 4. A média de pontuação obtida para sustentabilidade ambiental da comunidade nessa dimensão foi de 3,276 , numa escala de 0 a 4 , o que corresponde a 0,819 , numa escala de 0 a 1 . É uma pontuação relativamente elevada, com variação oscilando entre o mínimo de 2,000, no caso do indicador 3 , referente à percepção da degradação do solo, até o máximo de 3,967, no indicador 8 , referente ao consumo de energia renovável. A total concordância com o uso de energia de fontes renováveis na comunidade devese ao fato de que a totalidade dos moradores entrevistados utiliza energia solar em suas residências.

Os dados sugerem que a sustentabilidade dos componentes naturais recebe maior atenção por parte das lideranças e dos moradores da comunidade, que demonstram grande preocupação com o equilíbrio ecológico entre a localidade e o meio ambiente, no que diz respeito à qualidade 
da água, ao tratamento dos efluentes, à produção orgânica de alimentos, à utilização de bioarquitetura nas construções e à correta destinação dos resíduos sólidos. Tem-se observado que significativos investimentos, tanto de mão de obra quanto de ações e verbas, são destinados para estes indicadores. Grande parte dos entrevistados concorda que as águas residuais de Piracanga recebem o devido tratamento e que o cultivo orgânico é utilizado quando se trata de produção interna de alimentos. Os resíduos orgânicos vão para a compostagem e, posteriormente, se transformam em adubo para o plantio e jardinagem dos espaços internos. A reciclagem de resíduos para cooperativas da cidade vizinha de ltacaré é utilizada por praticamente todos os moradores de Piracanga.

Tabela 2. Nível de concordância dos entrevistados aos indicadores de sustentabilidade ambiental da comunidade, na dimensão social.

$\begin{array}{lllllllll}\text { Indicadores } & \mathrm{A} & \mathrm{B} & \mathrm{C} & \mathrm{D} & \mathrm{E} & \mathrm{F} & \sum \mathrm{Xp}_{\mathrm{ij}} / & \text { Total } \\ & (0) & (1) & (2) & (3) & (4) & & \mathrm{N} & \end{array}$

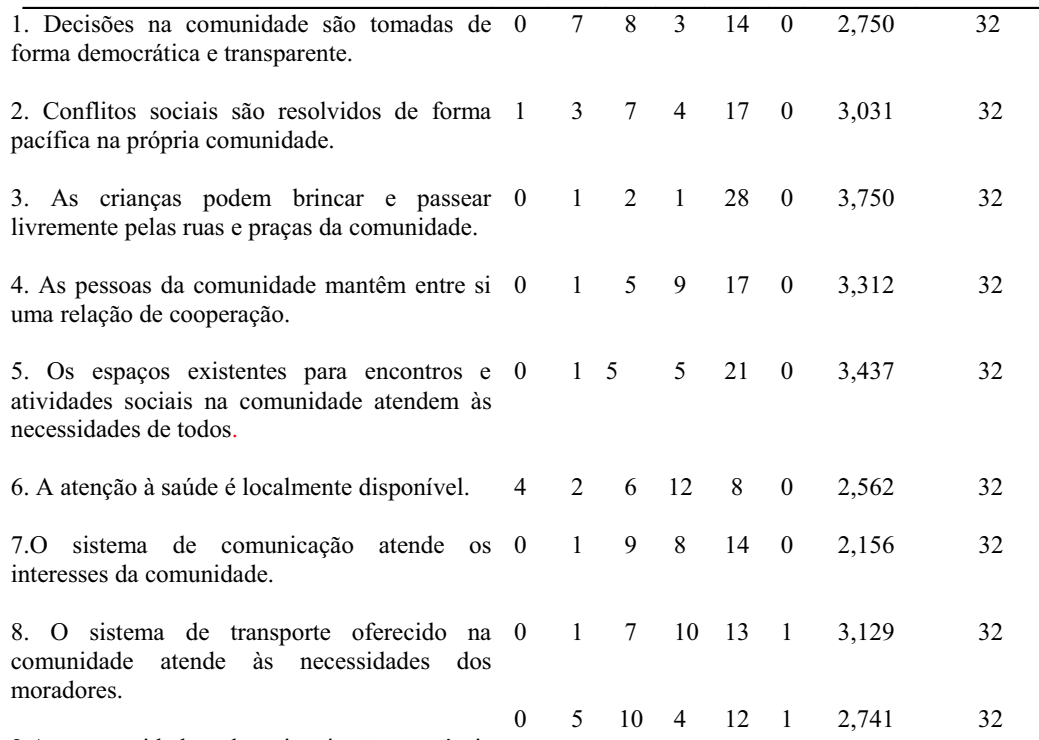

9.As oportunidades educacionais são acessíveis a todos dentro da comunidade.

10. A comunidade tem mecanismos para $\begin{array}{cllllllll}6 & 2 & 6 & 4 & 9 & 5 & 2,296 & 32\end{array}$ resolver problemas de desigualdades econômicas entre os moradores.

Índice médio obtido pela comunidade na 29,154/10 dimensão social $\sum\left(\mathrm{XP}_{\mathrm{ij}} / \mathrm{N}\right) / \mathrm{n} \quad 2,916 / 4=0.729$

Fonte: Elaboração dos autores.
Legenda: Legenda: A - Nunca; B - Raramente; C - Frequentemente; D - Geralmente; E - Sempre; $\mathrm{F}-$ Sem resposta. 
Tabela 3 - Nível de concordância dos entrevistados aos indicadores de sustentabilidade ambiental na dimensão econômica.

\begin{tabular}{|c|c|c|c|c|c|}
\hline Indicadores & $\begin{array}{c}\text { Nunca } \\
(0) \\
\end{array}$ & $\begin{array}{c}\text { Rara- } \\
\text { mente } \\
(1)\end{array}$ & $\begin{array}{l}\text { Frequente- } \\
\text { mente } \\
(2)\end{array}$ & $\begin{array}{l}\text { Geralmente } \\
\text { (3) }\end{array}$ & $\begin{array}{c}\text { Sempre } \\
\text { (4) }\end{array}$ \\
\hline $\begin{array}{l}\text { 1. Os moradores satisfazem suas necessidades de } \\
\text { alimentação e moradia na comunidade. }\end{array}$ & 0 & 2 & 1 & 9 & 19 \\
\hline $\begin{array}{l}\text { 2. Há oportunidade de trabalho suficiente para a } \\
\text { mão de obra local. }\end{array}$ & 1 & 1 & 9 & 7 & 13 \\
\hline $\begin{array}{l}\text { 3. Os recursos e serviços existentes na comunidade } \\
\text { atendem às necessidades dos moradores. }\end{array}$ & 0 & 4 & 4 & 15 & 8 \\
\hline $\begin{array}{l}\text { 4. As atividades de geração de renda locais são } \\
\text { suficientes para os membros da comunidade. }\end{array}$ & 0 & 6 & 8 & 9 & 9 \\
\hline $\begin{array}{l}\text { 5. Os jovens encontram na comunidade } \\
\text { oportunidades para desenvolverem seus talentos. }\end{array}$ & 1 & 6 & 6 & 8 & 10 \\
\hline $\begin{array}{l}\text { 6. Os alimentos consumidos na comunidade são } \\
\text { produzidos nela. }\end{array}$ & 2 & 22 & 4 & 0 & 3 \\
\hline $\begin{array}{l}\text { 7. O nível de renda familiar per capita na ecovila } \\
\text { atende às necessidades básicas dos seus } \\
\text { membros.* } \\
\text { Índice médio obtido pela comunidade na } \\
\text { dimensão econômica } \sum\left(\mathrm{XP}_{\mathrm{ij}} / \mathrm{N}\right) / \mathrm{n}\end{array}$ & 2 & 14 & 8 & 5 & 0 \\
\hline $\begin{array}{l}\text { Fonte: Dados da pesquisa } \\
\text { * Neste indicador, atribuiu-se pontuação de ac } \\
\text { entrevistados: } 0 \text { - sem rendimento, } \\
1 \text { - menos de um salário mínimo }(\mathrm{R} \$ 622,00 \text { na épo } \\
\geq \mathrm{R} \$ 3.000,00 \text {. }\end{array}$ & do co $2-$ & aixa & da famili & er capita d & rada pelos \\
\hline
\end{tabular}


Tabela 4. Nível de concordância dos entrevistados aos indicadores de sustentabilidade ambiental, na dimensão dos componentes naturais da comunidade.

\begin{tabular}{|c|c|c|c|c|c|c|c|c|}
\hline Indicadores & $\begin{array}{l}\text { A } \\
(0)\end{array}$ & $\begin{array}{l}\text { B } \\
(1)\end{array}$ & $\begin{array}{cc}\mathrm{C} \\
(2)\end{array}$ & $\begin{array}{l}\mathrm{D} \\
(3)\end{array}$ & $\begin{array}{l}E \\
(4)\end{array}$ & F & $\underset{\mathrm{N}}{\sum \mathrm{Xp}_{\mathrm{ij}} /}$ & Total \\
\hline $\begin{array}{l}\text { 1. As pessoas da comunidade se preocupam com o } \\
\text { equilíbrio ecológico no ambiente local. }\end{array}$ & 0 & 0 & 3 & 8 & 20 & 1 & 3,548 & 32 \\
\hline $\begin{array}{l}\text { 2. A quantidade de vegetação cresce regularmente } \\
\text { nos espaços da comunidade. }\end{array}$ & 0 & 0 & 6 & 7 & 18 & 1 & 3,290 & 32 \\
\hline $\begin{array}{l}\text { 3.Não se percebe aumento na degradação do solo } \\
\text { na área da comunidade }\end{array}$ & 5 & 0 & 20 & 0 & 5 & 2 & 2,000 & 32 \\
\hline $\begin{array}{l}\text { 4. A comunidade adota estratégias para } \\
\text { conservação dos recursos naturais no local. }\end{array}$ & 1 & 2 & 4 & 6 & 18 & 1 & 3,225 & 32 \\
\hline $\begin{array}{l}\text { 5. As construções na comunidade são projetadas } \\
\text { para minimizar o consumo de energia e } \\
\text { harmonizar com o ambiente local }\end{array}$ & 0 & 3 & 8 & 9 & 8 & 4 & 2,785 & 32 \\
\hline $\begin{array}{l}\text { 6. Os alimentos produzidos na comunidade são } \\
\text { cultivados organicamente. }\end{array}$ & 0 & 2 & 0 & 2 & 27 & 1 & 3,741 & 32 \\
\hline 7. As águas residuais são tratadas na comunidade. & 0 & 0 & 3 & 4 & 22 & 3 & 3,655 & 32 \\
\hline $\begin{array}{l}\text { 8. A energia consumida em sua residência é } \\
\text { gerada a partir de fontes renováveis (solar, eólica, } \\
\text { biomassa ou geotérmica). }\end{array}$ & 0 & 0 & 0 & 1 & 30 & 1 & 3,967 & 32 \\
\hline \multicolumn{9}{|l|}{ Índice médio de sustentabilidade da comunidade } \\
\hline na dimensão dos componentes naturais & & & & & & & $26,211 / 8$ & \\
\hline$\sum\left(\mathrm{XP}_{\mathrm{ij} / \mathrm{N}}\right) / \mathrm{n}$ & & & & & & & $\begin{array}{c}3.276 / 4= \\
0.819\end{array}$ & \\
\hline
\end{tabular}

Fonte: Elaboração dos autores.

Legenda: Legenda: A - Nunca; B - Raramente; C - Frequentemente; D - Geralmente; E - Sempre; F - Sem resposta. 


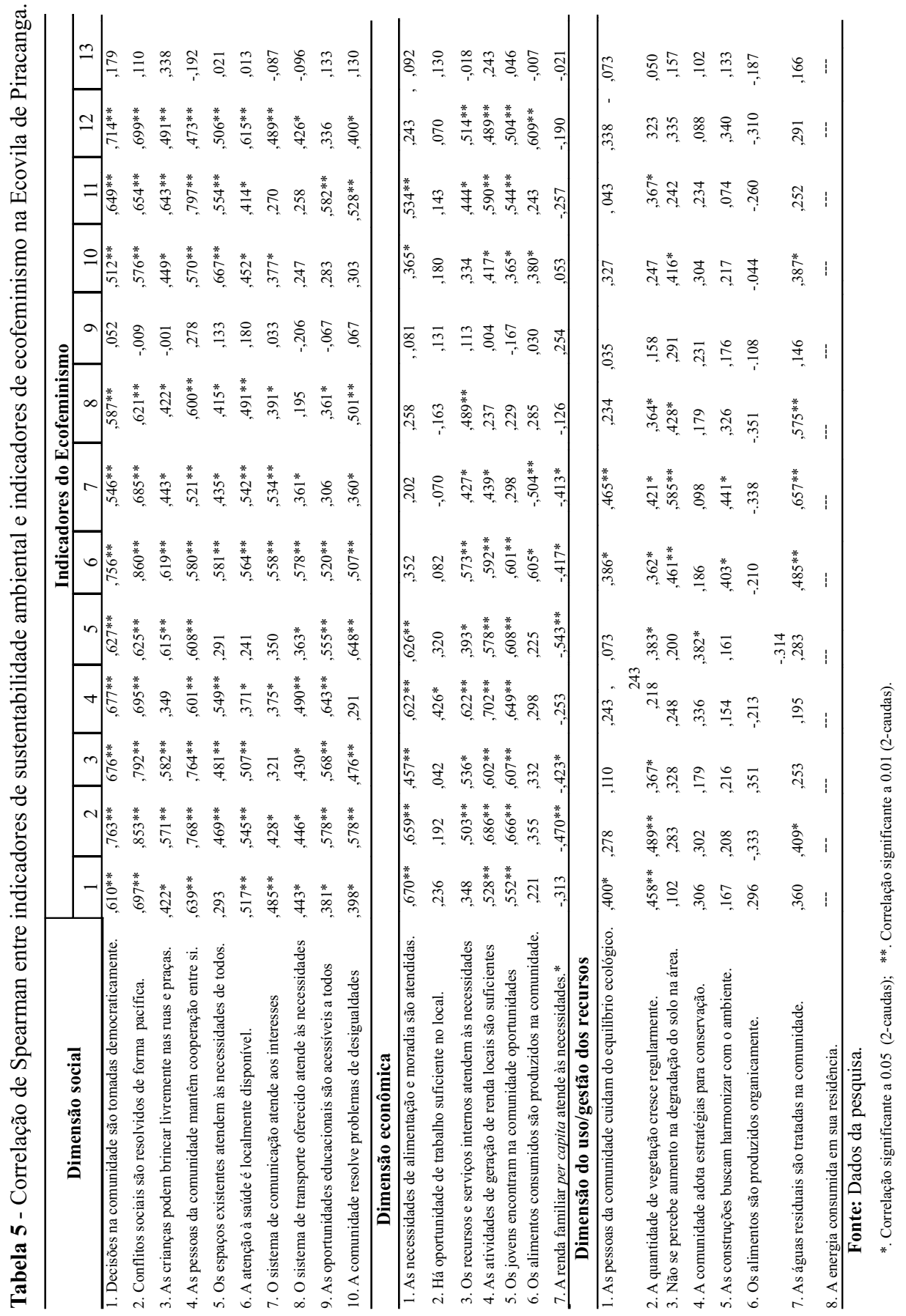




\subsection{Relação entre ecofeminismo e susten- tabilidade ambiental na comunidade}

Os dados da pesquisa confirmam não apenas a presença de grande parte dos valores ecofeministas na Ecovila de Piracanga como também apresentam correlação significante com a sustentabilidade ambiental, nas três dimensões consideradas (Tabela 5). A ausência total de correlação ou de correlação significante ocorre nos casos em que a totalidade ou quase totalidade dos entrevistados concordam, como no indicador 9 - o manejo e a recuperação dos ecossistemas é uma preocupação da comunidade -, e no indicador 13 - a comunidade considera que o planeta é um organismo vivo -, ou no indicador 8 do uso/gestão dos recursos, sobre o consumo de fontes de energia renováveis. Nesses casos, o indicador transforma-se numa constante ou quase constante.

Esses resultados confirmam, portanto, o pressuposto de que os princípios e valores defendidos pelo ecofeminismo contribuem para fortalecer e potencializar a sustentabilidade ambiental da comunidade. Tais resultados mostram que, quanto mais forem investidas ações para o fomento dos princípios e valores do ecofeminismo, provavelmente se terá maior sucesso no alcance da sustentabilidade ambiental da comunidade, mas, sendo negligenciados, poderão refletir negativamente. Nesse sentido, vale insistir na relevância de a comunidade investir no princípio da não hierarquização da organização, considerando que este foi um dos indicadores de menos concordância dos moradores, mas que tem efeito positivo significante, isto é, quanto menos hierarquizada, maior será a sustentabilidade ambiental da comunidade. É oportuno observar também que os que têm menor nível de renda familiar são os que mais discordam da existência de apoio às pessoas, de oportunidades iguais para o desenvolvimento de talentos, de valorização da estética, da arte e da beleza, de valorização da diversidade e de organização não hierarquizada na comunidade, de onde resultam correlações negativas significantes.

\section{Conclusão}

Os princípios e valores que orientam o ecofeminismo em favor do ambiente sustentável encontram suporte empírico na Ecovila de Piracanga que, por sua vez, se apresenta como uma organização social alternativa, de baixo impacto sobre os componentes naturais e de novos valores de bem-estar social. Princípios do ecofeminismo e práticas da ecovila apresentam-se consonantes com a tentativa de mitigar impactos antrópicos sobre o meio ambiente, em diferentes dimensões, em nível local, e questionar padrões culturais dominantes. 
Os resultados obtidos permitem concluir que, tanto a ecovila pesquisada ainda tem muito a evoluir como organização social alternativa que busca uma forma mais integrada de relacionamento humano com a natureza, e uma forma de convivência humana fundada na solidariedade e cooperação, quanto o movimento ecofeminista tem ainda muito a trabalhar na sua prática para tornar concretos os princípios e valores defendidos em favor da sustentabilidade do meio ambiente. Entretanto, os resultados não deixam dúvidas quanto à persistente relação positiva que existe entre indicadores de sustentabilidade ambiental e indicadores de ecofeminismo, sinalizando que esse movimento pode trazer relevantes contribuições para a formação de comunidades mais sustentáveis. Acima de tudo, os resultados apontam para a possibilidade de soluções inovadoras em busca de um novo padrão no relacionamento sociedade-natureza.

Como o movimento de ecovilas vem se expandindo no mundo e no Brasil, é altamente recomendável ampliar as avaliações empíricas de como se estrutura e como funciona, em diferentes contextos socioambientais, essa modalidade de organização social alternativa.

\section{Referências}

ALTIERI, Miguel A.; NICHOLLS, Clara I. Una perspectiva agroecológica para una agricultura Ambientalmente sana y socialmente más justa en la América Latina del siglo XXI. Berkeley: Universidad de Califórnia/Instituto Nacional de Ecologia. 2005. Disponível em: http://www2.inecc.gob.mx/ publicaciones/libros/363/cap12.html. Acesso: 5 dez. 2013.

ANGELIN, Rosângela. "Gênero e meio ambiente: a atualidade do ecofeminismo". Revista Espaço Acadêmico, n. 58, março 2006. Disponível em: <http://www.espacoacademi co.com.br/058/58angelin.htm >. Acesso em: 12 out. 2013.

BIANCHI, Bruna. "Introduzione - Ecofemminismo: il pensiero, I debattiti, le prospettive". Revista Deportate, Esuli, Profughe (DEP), n. 20, v. I-XXVI, Jul. 2012.

BRUNDTLAND, Gro Harlem. Nosso Futuro Comum. 2. ed. Rio de Janeiro, RJ: Fundação Getúlio Vargas, 1991. 430 p.

CAPRA, Fritjof. A teia da vida: uma nova compreensão científica dos sistemas vivos. 9. ed. São Paulo: Cultrix, 2000. 249 p.

CARNEIRO, Beatriz Helena Scigliano. ECOFEMINISMO E GESTÃO PLANETÁRIA. ENCONTRO ESTADUAL DE HISTÓRIA-ANPUH-SP, 21., Campinas, SP. Anais... Campinas, SP, setembro, 2012. Disponível em: <http://www.encontro2012.sp.anpuh.org/ resources/anais/17/1342323229_ARQUIVO_ANPUH.2012. pdf $>$. Acesso em: 12 out. 2013.

COLEMAN, James S. "Social Capital in the Creation of Human Capital”. AJS, v. 94, Supplement, p. 95-120, 1988. 
CUNHA, Eduardo. "A Sustentabilidade em ecovilas: desafios, propostas e o caso da Ecoovila 1 - Arcoo". Revista de Gestão Social e Ambiental, v. 4, n. 1, p. 113-126, jan./abr. 2010.

DI CIOMMO, Regina Célia. "Relações de gênero, meio ambiente e a teoria da complexidade". Revista Estudos Feministas, v. 11, n. 2, p. 423-443, jul./dez. 2003.

D'EAUBONNE, Françoise. Le féminisme ou la mort. Paris: Pierre Horay, 1974. 276 p.

EAST, May et al. Programa de Educação Gaia: Educação para o design de ecovilas. Instituto das Nações Unidas para Treinamento e pesquisa. Tradução: Maria Christina Pinheiro, Gaia Education/Secretaria do Verde e do Meio Ambiente de São Paulo, 2005. 114 p.

EISLER, Riane. O Cálice e a Espada: Nossa História, Nosso Futuro. Rio de Janeiro: Imago Editora, 2007. 266 p.

GARCIA, Sandra Mara. "Desfazendo os Vínculos Naturais Entre Gênero e Meio Ambiente". Estudos Feministas, n. 0, p. 163-167, jul./dez. 1992.

GRIFFIN, Susan. Women and Nature: The Roaring Inside Her. San Francisco: Harper \& Row. 1978. 300 p.

HÉBRARD, Monique. Mulher e Homem: uma aliança de futuro. São Paulo: Paulinas, 1994. 179 p.

HERRERO, Yayo. Ecofeminismo: una propuesta de transformación para un mundo que agoniza. 2007. Disponível em: $<$ http://www.rebelion.org/noticia. php?id $=47899>$. Acesso em: 30 ago. 2013.

JORGE, Marco Aurélio P. Sustentabilidade e desenvolvimento local: estudo de projeto na formação da Ecovila Viver Simples em Itamonte, MG. 2008. 162 f. Dissertação (Mestrado em Gestão Empresarial) - Centro de Formação Acadêmica e Pesquisa da Escola Brasileira de Administração Pública e de Empresas, Fundação Getulio Vargas, Rio de Janeiro.

JACKSON, Ross. The ecovillage movement. Permaculture Magazine, University of New South Wales, n. 40, p. 1-15, Summer 2004.

KING, Ynestra. Curando as feridas: Feminismo, Ecologia e Dualismo Natureza/ Cultura - Gênero, Corpo e Conhecimento. Rio de Janeiro: Record: Rosa dos Tempos, 1997.

LANGHELLE, Oluf. "Sustainable development and social justice: expanding the Rawlsian framework of global justice". Environmental Values, v. 9, n. 3, p. 295-323, 2000.

MCLELLAN, David. Karl Marx: Selected Writings. The German Ideology. New York: Oxford University Press, 1978. p. 159194.

MELLOR, Mary. Feminism \& Ecology. Cambridge: Polity Press 1997. $221 \mathrm{p}$. 
MURARO, Rose Marie. Feminino e masculino: uma nova consciência para o encontro das diferenças. Rio de Janeiro: Sextante, 2002. $287 \mathrm{p}$.

NORTH, Douglass C. Institutions, Institutional Change and Economic Performance. Cambridge University Press. 1990. $152 \mathrm{p}$.

OLIVEIRA, Naia. Grupos Mulheres da Terra: abordagem fundamentada no ecofeminismo e na alfabetização ecológica. Mulher e Trabalho, v. 5, p. 101-112, 2005. Disponível em: <http://revistas.fee.tche.br/index.php/ mulheretrabalho/article/view/2716/3039>. Acesso em: 11 out. 2013.

ORTNER, Sherry. B. "Is Female to Male as Nature Is to Culture?" In: ROSALDO, M. Z. LAMPHERE, L. (eds.), Woman, Culture, and Society, Stanford, CA: Stanford University Press, 1974. p. 68-87.

PLANT, Judith. "Searching for Common Ground: Ecofeminism and bioregionalism". In: DIAMOND, Irene; ORENSTEIN, Gloria Feman. Reweaving the World: The Emergence of Ecofeminism. San Francisco: Sierra Club, 1990. 320 p. p. 155-172.

PUTNAM, Robert. Comunidade e Democracia; A Experiência da Itália Moderna. Rio de Janeiro: Ed. FGV. 1993. 257 p.

RUETHER, Rosemary R. New Woman, New Earth: Sexist Ideologies and Human Liberation. New York: Seabury Press, 1975. $221 \mathrm{p}$.

. "Ecofeminism: Symbolic And Social Connections of The Oppression of Women And The Domination of Nature." Feminist Theology, 3, p. 35-50, 1995.

SACHS, Ignacy. Estratégias de transição para o século XXI: desenvolvimento e meio ambiente. São Paulo: Studio Nobel: Fundap, 1993. 103 p.

SANDILANDS, Catriona. The Good-Natured Feminist: Ecofeminism and the Quest for Democracy. Mineapolis, MN: The University of Minesota Press, 1999. 245 p.

SANTOS JR., Severiano José dos. "Ecovilas e Comunidades Intencionais: Ética e Sustentabilidade no Viver Contemporâneo". ENCONTRO DA ANPPAS, 3., Brasília, DF: CEFET/BA; CDS-UnB, 2006. Disponível em: < http://www.recriarcom voce.com.br/blog_recriar/ecovilas-e-comunidadesintencionais-etica-e-sustentabilidade-no-vivercontemporaneo/>. Acesso em: 12 dez. 2013.

SEN, Amartya Kumar. Desenvolvimento como liberdade. São Paulo: Companhia das Letras, 2000. 461 p.

SILIPRANDI, Emma. "Ecofeminismo: contribuições e limites para a abordagem de políticas ambientais". Agroecologia e desenvolvimento sustentável, v. 1, n. 1, p. 61-70, jan./mar. 2000. 
"Um olhar ecofeminista sobre as lutas por sustentabilidade no mundo rural". In: PETERSEN, Paulo (Org). Agricultura familiar camponesa na construção do future. Rio de Janeiro: AS-PTA, 2009. p. 139-151.

SVENSSON, Karen; JACKSON, Hildur (Orgs.). Ecovillage living: restoring the earth and her people. Devon, UK: Green Book and Gaia Trust, 2002. 181 p.

WARREN, Karen; CHENEY, Jim. "Ecological Feminism and Ecosystem Ecology". Hypatia, v. 6, n. 1, p. 179-197, Spring 1991.

WARREN, Karen; WELLS-HOWE, Barbara. Ecological Feminism. Cambridge: Routledge, 1994. 209 p.

WARREN, Karen. "Introduction to Ecofeminism." In: ZIMMERMAN, Michael E.; CALLICOIT J. Baird; SESSIONS, George; WARREN, Karen J.; CLARK, John (Eds.). Environmental Philosophy: From Animal Rights to Radical Ecology. Englewood Cliffs, NJ: Prentice-Hall, 2005. 495 p. p. 253-267.

YUNUS, Muhammad et al. Estado do Mundo, 2010: estado do consumo e o consumo sustentável. Introdução. Salvador, BA: UMA - Universidade Livre da Mata Atlântica Ed. 2010. $268 \mathrm{p}$

ZAMBERLAN, Jurandir; FRONCHETI, Alceu. Preservação do pequeno agricultor e o meio ambiente. Petrópolis: Vozes, 2001. 214 p.

[Recebido em 13 de novembro de 2013 e aceito para publicação em 9 de outubro de 2014]

\section{Ecofeminism and Sustainable Community}

Abstract: It is assumed that the ecovillage movement represents a social organization alternative with low impact on natural environment and new values in accordance with the social life welfare. The ecofeminist movement, on its turn, sustains that the main concern of the movement is towards environmental protection and against destructive technology. It is investigated, in this research, if the ecofeminism principles are present at the ecovillage organization and dynamics, and if ecofeminist indicators impact on the quality of local environment. The Piracanga Ecovillage, located at municipality of Marau, South Cost of Bahia, Brazil, has been taken for empirical observation. Findings support the assumption that there is a significant correlation between environmental sustainable indicators and ecofeminism indicators at the local level, pointing towards innovative solutions for society-nature relationship.

Key Words: Ecofeminism. Ecovillages. Sustainable Communities. Local Development.

34 Estudos Feministas, Florianópolis, 23(1): 11-34, janeiro-abril/2015 